\title{
Research Review on the Communication Effects of Government New Media
}

\author{
Bin Liu \\ Management department \\ Jiangsu Police Institute \\ Nanjing, China \\ Liubin000@163.com
}

\begin{abstract}
In recent years, government new media is in full swing, and it has undeniable role and future prospects. However, there also exist many problems in its development. Throughout the domestic and foreign scholars' studies on government affair new media, especially the public-government relations paradigm and the government-public relations paradigm built by foreign scholars for government affair new media, which plays a significant enlightenment role in the China's government functions transformation and better playing the roles of new media.
\end{abstract}

Keywords-government new media; communication effect; literature review

\section{INTRODUCTION}

In “China E-Government Yearbook (2014)" at the end of November 2014, China's government micro blog authentication accounts (including the two platforms, Sina Weibo and Tencent) reached 277,000, and the total number of people reached 4.39 billion; central state organs' government micro blog certified accounts reached 219, totally covering people of 270 million; and provincial and subnational government units micro blog certification accounts reached more than 194,000, covering a total number of 20.8 million people. As of September 30, 2014, nearly 6000 government affair Wechat accounts have settled in Wechat platform, throughout all the regions of the country. The Internet has make government one important part in the social-ecological system (Tim O'Reilly, 2010); new media has reshaped China's public life and has made public opinion ecology undergo significant changes. In the development situation of new media, people's public life has new contents and features (Tong Bing, 2011), and the "new media in politics" has become the new government communication channel (Yu Deshan, 2015); the year of 2011 is known as "the First Year of Chinese government Affair Micro Blog”, and more and more government agencies and officials all over the country open micro blogs as a channel for information publication and platform of serving the public, way of understanding public opinions and the space of interacting with people. "Opinions of General Office of the State Council on Further Strengthening of the Government Information Disclosure, Response to Social Concerns and Enhancing the Government Credibility" was released on October 15, 2013, in which government micro blog was mentioned for seven times. In the anti-corruption storm of 2014, the website of Central Commission for Discipline Inspection
Department has played an important role and become the first source of releasing authoritative anti-corruption information. In August 2014, the Fourth Session of the Central Leading Group for comprehensively deepening the reform examined and adopted the "Guiding Opinions on Promoting the Integration Development of Traditional Media and New Media”, and in December 2015, President Xi Jinping keystroked and posted a micro blog greeting during the inspection in Liberation Army Newspaper Office. In February 2016, President Xi Jinping conducted field research in the People's Daily, Xinhua News Agency and China Central Television, and then hosted the conference of the Party's press and public opinion jobs. He proposed to effectively improve the Party's force, guidance, influence and credibility of news public opinions, promote the integration development, actively draw support from the advantages of new media communication, adapt to the communication trend of demassification and differentiation, and accelerate the construction of a new pattern of public opinion guidance. On April 19, 2016, the central network and information security group leader, $\mathrm{Xi}$ Jinping, hosted the network security and information work forum in Beijing and delivered an important speech that all levels of party and government organs and leading cadres should learn to follow the mass line through the network.

The advent of Twitter in March 2006 enables this emerging media and technology to have the enormous potential of changing the political agenda and promoting social movements. Foreign government agencies are also trying to enter social media (Lampe, LaRose, Steinfield, and DeMaagd, 2011) through the relevant technology; in May 2008, US government employees launched GovLoop (http://www.govloop.com), and the website has now connected 25,000 federations, states, local government employees, scholars and related staff (Dadashzadeh, 2010). In April 2010, the US federal government announced the launch of its own social media site, FedSpace. According to statistics, about $80 \%$ of public organizations and departments are using new media (Bonsón et al., 2012 and Snead, 2013). UN E-Government Survey of 2012 shows that among 193 member countries, there have been 92 countries' governments adopting different forms of social media, and many national government agencies are using Facebook and micro blog(Bonsón et al., 2012 and Kavanaugh et al ., 2012). Meanwhile, in order to meet the majority of different public needs on platforms, government agencies have 
launched their own social media publishing and commenting contents (Ku, Chen, \& Zhang, 2013).

The spreading of government new media has not only changed the model of the communication between government and public, but also decisively make public administration move towards a new and open pattern, leading to the emergence of new governance paradigm (Maria Karakiza, 2015) and a new relationship pattern. It is in this context that the development of government new media becomes not only the focus of governments at all levels, but also major issue of academic research. In this paper, the spreading effects of new media home and abroad are sorted out, and ti is hoped that it can provide reference for the development of China's government new media

\section{CONSTRUCTION OF GOVERNMENT-PUBLIC RELATIONS PARADIGM IN GOVERNMENT NEW MEDIA}

Innovative mode of government new media communication increases government transparency and encourages citizens to participate in government decision (Harris et al., 2009, Sadeghi, 2012, Searson and Johnson, 2010 and Welch and Hinnant, 2003). The nature of online media is considered as promoting citizen to obtain government information, so as to inspire them to share and participate in the process of government decisionmaking (Searson \& Johnson, 2010). Transparency and interactivity are two major components of government's website. They believe that transparency is achieved through the dissemination of information and mainly mutual interaction (Welch \& Hinnant, 2003). Furthermore, transparency and accountability can also reduce government corruption (Kim et al., 2009, Maor, 2004, Lio, Liu, \& Ou, 2011), help improve the relationship between the public and the government (Chadwick, 2009, Coursey and Norris, 2008, Ho, 2002, Moon, 2002, Tolbert and Mossberger, 2006, Welch et al., 2005 and West, 2004, Karen Mossberger, Yonghong Wu, JaredCrawford, 2013), and strengthen the dialogue between public and government (Bertot, Jaeger, \& Grimes, 2012).

The function of new media in mobile government is that utilizing mobile technology to change the process of governance or the interaction between the users and government (World Bank, 2012). For example, the Peer to Patent platform of the United States Patent Office allows industry, academia and the general public to provide relevant knowledge and evidence for patent examiners to help determine the validity of the patent application (Noveck, 2009). APP "My Nanjing” provides local information services of Nanjing, and offers functions such as quering the accumulation fund social security payment, license scoring and doctor appointments on the phone. Jiangsu Public Security "micro Policing” Platform cluster the masses, so that they can log in the Wechat platform on mobile phone, and 578 businesses such as household register, police and immigration can be extended from windows of the public security organs to the Internet and personal, which truly realizing "make the data run frequently and make people move less." Government new media can also reduce the administrative burden of companies (Arendsen, Peters, terHedde, \& van Dijk, 2014), and provide online information to prevent women from domestic violence (Wathen \& McKeown, 2010).
Finally, as to the value construction and social control, high-quality government websites can not only promote the credibility of website and government (Searson and Johnson, 2010) but also enable the public to take advantage of the impact of new media as much as possible to understand political information, participate political activities, interacte and discuss with the political parties in the Internet era, which is conducive to the formation of their political identity. (Chen Wensheng, 2015)

\section{CONSTRUCtion OF PUBLIC-GOVERNMENT RELATIONS PARADIGM In GOVERNMENT NEW MEDIA}

Network politics has become the norm, and mass politics has officially entered the public view (Li Liangrong, 2011). Government new media is an effective communication channel that allows citizens to participate in democratic institution and political process, creating value for citizens and government (Enrique Bonsóna, Sonia Royob, Melinda Ratkaia, 2015). Governments increasingly consult advice from public online through "E-participation" and "E rules" (Carlitz \& Gunn, 2002). Scotland and England let the citizens vote for parliament through the "E-petition"; Chile has launched the "Virtual Senate" mechanism to help citizens regulate laws (Padget, 2005); and Sweden pushes the "E-democracy" party, in which the voting it represents is voted by online public (Boyd, 2008). In the interaction, the most performance is political participation, that is, the activities of trying to influence policy or government actions (Verba et al., 1995). Expressing political views through the network is also an important way of political participation. The use of social media is conducive to citizens' political participation and interaction (Gil de Zúñiga et al., 2009 and Macafee and Simone, 2012), and the Internet makes possible all kinds of political activities, such as writing letters to politicians, visiting the campaign website, and online donations (Gibson et al., 2005), in which the blog also positively impacts on the public's political participation (Gil de Zúñiga et al., 2009); besides, more and more social networking websites are participating in political activities, especially campaign (Gueorguieva, 2008). Many studies on the government new media abroad have focused on the political elections (Bo Nilsson \& Eric Carlsson, 2014, W. Lance Bennett, 2012).

In addition, the government new media can strengthen the organization and communication; encourage collaboration and information sharing with the public and track real-time incidents (Ostrow, 2009). It can use the collective wisdom of the public to complete the mission of the government and cultivate audience participation (MyonghoYia, Sam GyunOhb, SunghunKimb, 2013). "Government and You” E-government strategy of Singapore Government is seeking to promote cooperative government that closely connect public and government (the Gov Monitor, 2010); the British government's great social program aims at substantially delegate rights to people (Cameron, 2010a); and Obama's advocacy of Open Government not only emphasizes the transparency of the government but also enhances the involvement and cooperation (Linders \& Wilson, 2011). The South Korean government's using standards of the new media are openness, timeliness, interactivity and controllability of information (Han, Cho, Lee, Choi, \& Kim, 2011). Government new media plays a very 
important role in promoting cooperation and the formulation of public policies, addressing social and political issues and making political and democratic dialogue in the political sphere (Mergel (2012b), Bertot, Jaeger, and Grimes, 2010, and Bertot, Jaeger, and Hansen, 2012).

\section{STUdy ON CHINA’S GOVERNMENT NEW MEDIA COMMUNICATION}

At present, Chinese scholars and government practitioners carry out researches from the perspective of subjects such as sociology, political science, public policy and public administration, and they mainly focus on the perspective of communication and public management. For example, Qu Xusheng studies management risk and operational strategies of government micro blogs. Du Yonghong analyzes the countermeasures to promote the social management innovation through government micro blogs. Liu Rui and Xie Gengyun conduct research on the current situation, problems and countermeasures of Chinese government micro blog operating. Zhang Ning investigates the propagation behavior and characteristics of the three government micro blogs of Guangdong Province: "Guangzhou Public Security", "Flowers Opening in Dongguan" and "Guangdong Communist Youth League" from the perspective of government communication. Shi Jing mainly relates to the basic status, government functions, communication effects, public opinion influence, management and development of government micro blogs. $\mathrm{Bi}$ Sheng makes related studies and sorts out the credibility of government micro blogs from the view of authority and influence of the media. Zhang Ling takes the development of government micro blog in Beijing as an example to analyze the current bottlenecks in the development of government micro blog, and to explore ways to overcome them. Ding Yi, Wang Yimin and Liu Suhong study the government micro blog application the shaping of government image. Wang Fei, Wang Baoming and Pang $\mathrm{Yu}$ discuss the strategies of government microblog when faced with virtual social crises. Wu Xiaojun and Gong Jie take “@ Peace Southern Guangdong” as the case to have analysis on the releasing methods, features and strategies of government micro blog information. Yu Rui analyzes the features and communication skills of government micro blog. Wang Wenhui and Chen Xian propose the thoughts on enhancing the effectiveness of government micro blog. Jiang Shenghong strengthens the crisis response to network public opinion by using government micro blog.

Moreover, there are also some scholars using methods of network analysis and questionnaire to have researches. For example, Sun Houquan, Wang Dongdong and Zhang Junli select the leaders of government micro blog opinions in Sina Weibo as the study sample, and adopt the method of social network analysis to analyze the social network structure of the leaders of government micro blog opinions and study the issues such as the density, centrality, location and role of the social networks. Du Yangqin, Huo Youguang and Suo Zhihai make an empirical analysis on the micro social network structure of government micro blog. Yu Jing and Fu Xuesong take the currently influential and representative government micro blog "Shanghai issuing" platform as a case study, apply the relevant theories of communication and administrative science as guidance, and use the methods of text analysis and questionnaire to analyze the published contents and audience feedback and summarize the reasons for the success and problems.

\section{Enlightenment of Government New Media Home And ABROAD}

Although currently, the development of China's government new media in full swing, and its role and future prospects have received more and more attention, there still exist problems in its operation: the imbalance between its booming in number and its development, and the lack of professionalism and affinity (Yin Jun, Jiang Shenghong, 2015). In the studies of the communication effects of government new media, Chinese and foreign scholars mostly concentrate on the study of its transparency, accountability and e-participation. However, the research on China's government new media communication should focus on its political advocacy and construction of ideology, not merely the function. Therefore, we should pay more attention to its public opinion orientation and the four "firm adherence". The research on government new media should not be solely limited to the public service, and more importantly, it should be settled in the value construction and social control. Thus, literature of the government new media home and abroad is sorted out in this paper, and the purposes are as follows. Firstly, it is hoped to help construct a new development pattern of government new media. By building government new media platform, erect the new government political network platform with the functions of significant information releasing, important policy advocacy, public services development, public opinion guidance, social conditions and public communication and social supervision and feedback in one, so as to create promote the flagship political advocacy new media with powerful influence. Secondly, it is hoped to follow the propagation law of Internet and find proper propagation path for government new media, thus enriching the spreading of new media. Thirdly, it is expected to contribute to the transformation of government administration philosophy and improve government competence in the network society. At the same time, the development of government new media is also conducive to the changes of public administration style and the adjustment of organization culture and structure.

\section{ACKNOWLEDGEMENTS}

*Fund Projects: College Philosophy and Social Science Fund Program of the Education Department in Jiangsu Province 2014SJB239; Scientific Research Project of Jiangsu Police Institute 2014SJYSY17; Funding Project of Leading Discipline Construction Engineering of Universities in Jiangsu Province.

\section{REFERENCES}

[1] KarenMossberger,YonghongWu,JaredCrawford,Connecting citizens and local governments? Social media and interactivity in major U.S. cities[J].Government Information Quarterly,2013(10)

[2] MyonghoYi,SamGyunOh,SunghunKim,Comparison of social media use for the U.S. and the Korean governments[J].Government Information Quarterly,2013(07) 
[3] Rebecca Ping Yu,The relationship between passive and active nonpolitical social media use and political expression on Facebook and Twitter[J].Computers in Human Behavior,2016(05)

[4] YonghwanKim,Hsuan-Ting Chen,Social media and online political participation: The mediating role of exposure to cross-cutting and likeminded perspectives[J].Telematics and Informatics,2016(05)

[5] JunpengGuo, Zengguang Liu, Yu Liu,Key success factors for the launch of government social media platform: Identifying the formation mechanism of continuance intention[J]. Computers in Human Behavior,2016(02)

[6] Dennis Linders, From e-government to we-government: Defining a typology for citizen coproduction in the age of social media[J]. Government Information Quarterly,2012(10)

[7] Stanley J. Baran ,Dennis K. Davis ,Mass Communication Theory: Foundations, Ferment, and Future[M]. Cengage Learning, 2014

[8] Tomasz Janowski ,Digital government evolution: From transformation to contextualization[J]. Government Information Quarterly,2015(07)

[9] JunpengGuo, Zengguang Liu, Yu Liu,Key success factors for the launch of government social media platform: Identifying the formation mechanism of continuance intention[J].Computers in Human Behavior, 2016(02)

[10] Enrique Bonsóna, Sonia Royob,MelindaRatkaia,Citizens' engagement on local governments' Facebook sites. An empirical analysis: The impact of different media and content types in Western Europe[J]. Government Information Quarterly, 2015(01):52-62
[11] Liu Hailong, Mass Communication Theory: Paradigm and Schools [M]. Beijing: China Renmin University Press, 2008

[12] Yin Jun\& Jiang Shenghong, Development Status and Countermeasures of Government Affair New Media [J]. Press Circles, 2015(05)

[13] Chen Ran, Empirical Study on Public Adoption of Government Affair New Media in the "Double Micro Linkages" Mode [J].E-Government, 2015(09)

[14] Meng Jian\& Huang Yan, Media Fusion Development and Modern Social Advancement-Thinking on China's Push of “Media Fusion Strategy [J]. News Devotee, 2014(12)

[15] Yu Deshan, Development of China's Government Affair New Media Application and Transformation of Public Information Governance [J].Theory Discussion, 2015(04)

[16] Dong Guang’an, Liu Siyang, Anomy and Countermeasures of Mobile Network Public Realm in the "Double Micro" Context [J].Zhengzhou University Journal(Philosophy of the Social Sciences), 2014(04)

[17] Zhu Huaxin, Micro Blog National Team: Improving Internet Public Opinion Ecology [J]. News Front, 2013(08)

[18] Chen Wensheng, Practice and Implication of Foreign Political Parties' Seeking Advice from Netizens on Micro Blog[J]. Social Sciences Abroad, 2015(06)

[19] Su Yuanhao \& Zhang Kun, “China Power” of Micro Blog[J]. Modern Media, 2012(10)a

[20] Liu Pengfei, Internet Public Opinion trend and Social Public Opinion Situation in 2013[J].Journalists, 2014(01) 